\title{
Referencialidade, coesáo estrutural e organizaçáo temporal em In Nomine a 3 de Brian Ferneyhough
}

\author{
Pedro Henrique de Faria \\ Universidade Federal do Piauí | Orcid: 0000-0002-2694-5518
}

\begin{abstract}
Resumo
O estudo analítico investiga os princípios estruturantes formais, temporais e rítmicos de In Nomine a 3 de Brian Ferneyhough. A análise parte da contextualização dos elementos referenciais da temática do ciclo Umbrations no qual a peça está inserida. Em seguida, é realizado um estudo detalhado da macroforma baseado na segmentação formal da peça e nas principais características organizacionais dos materiais correlacionados à temática. A última parte da análise dedica-se ao estudo minucioso dos aspectos temporais e rítmicos no âmbito da microforma da peça a partir das subseçóes e dos compassos individuais. A aproximação analítica empregada recorre a um conjunto de estratégias alternativas a fim de identificar e discutir os elementos estruturantes da peça inacessíveis por meio da análise tradicional da partitura, contextualizando-os ao pensamento composicional de Ferneyhough.

Palavras-chave: Brian Ferneyhough, In Nomine a 3, análise musical, composição musical.

\section{Referenciality, Structural Cohesion and Temporal Organization in In Nomine a 3 by Brian Ferneyhough}

\section{Abstract}

The analytical study investigates the formal, temporal and rhythmic structuring principles of In Nomine a 3 by Brian Ferneyhough. The analysis starts with the contextualization of the referential elements of the Umbrations cycle, in which this piece is included. The analysis follows with a detailed study of the macro form of the piece, based on its formal segmentation and the main characteristics of the music material related to the thematic. The last part of the analysis is dedicated to the investigation of the temporal and rhythmic aspects in the microform, based on the study of the subsections and the individual measures. The analytical approach employs a set of alternative strategies to identify and discuss the structuring elements of the piece that are inaccessible by the traditional analysis of the score notation, allowing a consistent contextualization to Ferneyhough's compositional thinking.
\end{abstract}

Keywords. Brian Ferneyhough, In Nomine a 3, Music analysis, Music composition.

\section{Referencialidad, cohesión estructural y organización temporal en In Nomine a 3 de Brian Ferneyhough}

\section{Resumen}

El estudio analítico investiga los principios estructurantes formales, temporales y rítmicos de In nomine a 3 de Brian Ferneyhough. El análisis parte de la contextualización de los elementos referenciales de la temática del ciclo Umbrations, del cual la pieza analizada forma parte. Seguidamente, se lleva a cabo un estudio detallado de la macroforma basado en la segmentación formal de la pieza y en las principales características organizacionales de los materiales correlacionados a la temática. La última parte del análisis se dedica a estudiar minuciosamente los aspectos temporales y rítmicos en el ámbito de la microforma de la pieza a partir de las subsecciones y de los compases individuales. El enfoque analítico empleado recurre a un conjunto de estrategias alternativas a fin de identificar y discutir los elementos estructurantes de la pieza, inaccesibles por medio del análisis tradicional de la partitura, en el contexto del pensamiento composicional de Ferneyhough.

Palabras clave: Brian Ferneyhough, In Nomine a 3, análisis musical, composición musical. 


\section{Gênero In Nomine, ciclo Umbrations e referencialidade ${ }^{1}$}

In Nomine a 3 (2001), do compositor inglês Brian Ferneyhough (1943), é uma miniatura 2 para piccolo, oboé e clarinete composta em referência ao gênero homônimo de música polifônica instrumental inglesa do período renascentista. Esta peça é a primeira de um ciclo denominado Umbrations3 que homenageia Christopher Tye (c. 1505-1573), compositor renascentista que possui o maior número de In Nomine disponíveis, são 24 ao todo.

Desde a década de 70 Ferneyhough começou a interessar-se pelas diversas formas de interação entre a sua experiência composicional e os aspectos extramusicais, como a pintura, a literatura, a filosofia e a ciência. Não se trata de tentar reproduzir em termos sonoros as sensaçôes visuais, verbais e abstratas, mas de estimular através do conflito entre essas diversas disciplinas espirituais uma espécie de "alquimia" de qualidades de sensaçôes: fonte de fertilizaçóes de formas hipotéticas ou modelos de processos formais concretos. (KOZU, 2003, p. 79)

Este ciclo destaca-se por ser o primeiro de Ferneyhough que utiliza referências musicais e estilísticas de outro compositor ${ }^{4}$. Em Umbrations, o elo unificador é a abordagem das "tradiçôes inglesas".

A exploração recente dos 'materiais emprestados' é representativa não apenas de um longo interesse no repertório renascentista, mas o engajamento específico com compositores ingleses incluindo Byrd e Tye sugere uma tentativa em reivindicar para si uma 'tradiçáo inglesa' [...] Se o engajamento de Ferneyhough com Tye pode ser compreendido, em parte, como uma identificação com sua 'tradição inglesa' (Englishness), então a escolha de tais exemplos primordiais podem representar outra 'concretização do ato de compor', uma 'observância criativa' de si mesmo como um compositor inglês [...] como um ato de recuperação de uma herança pessoalmente 'aceitável' com alguma remoção histórica de sua herança imediata. (FITCH, 2013, p. 243-244, tradução nossa)

A abordagem das tradições inglesas no contexto definido por Fitch caracteriza o que chamamos de "temátică" do ciclo. A adoção desta temática no discurso composicional de Ferneyhough reflete objetivamente na incorporação de diversos elementos que fazem alusão ao gênero "In Nomine", à linguagem pré-tonal renascentista e ao estilo de Tye em In Nomine a 3. Esses elementos de referencialidade são fundamentais na estruturação do discurso musical e na coesão formal desta composição. $\mathrm{O}$

1 O termo "referencialidade" é definido neste trabalho como o conjunto de características musicais identificadas na peça que remetem ou fazem alusão à temática do ciclo Umbrations.

2 O termo "miniatura" enfatiza a principal característica deste formato de composição em In Nomine a 3, a brevidade temporal. De acordo com Hepburn (2006, p. 93), miniaturas contêm tipicamente entre 30 segundos e dois minutos de duração. A gravação de referência da peça (IN NOMINE 2004) contém dois minutos de duração.

3 In Nomine a 3 pertencia a um conjunto de peças denominado "Projeto Tye" (FITCH, 2013, p. 243). Mençôes sobre o ciclo Umbrations surgem apenas a partir do ano de 2017, nas partituras de In Nomine a 5 e In Nomine a 12. No catálogo de peças de Ferneyhough, publicado em 2018 pela Edition Peters, In Nomine a 3 consta como a primeira peça deste ciclo.

4 Fitch (2013) cita que o primeiro projeto composicional de Ferneyhough sobre o gênero In Nomine ocorreu em Three Pieces of William Byrd (1963), peça que nunca foi publicada. 
emprego dos elementos musicais referenciais combinados com o estilo composicional típico de Ferneyhough tornam esta peça um exemplo substancial da temática de Umbrations. Um relevante exemplo da referencialidade encontra-se na abertura da peça, onde a parte do clarinete contém as primeiras 12 notas do cantus firmus da antífona Gregoriana Gloria tibi Trinitas (vide exemplo 1). Conforme apontam Donington e Dart (1949, p. 101) e Reese (1949, p. 8), esta melodia, geralmente composta por 52 notas, é a referência para a criação da polifonia instrumental de todos os In Nomine tradicionais. Esta é a única ocorrência da referencialidade na peça em que Ferneyhough cita de forma literal o material musical deste gênero. As demais ocorrências fazem alusão às estruturas tonais, recorrendo apenas a materiais escalares e tríades maiores.

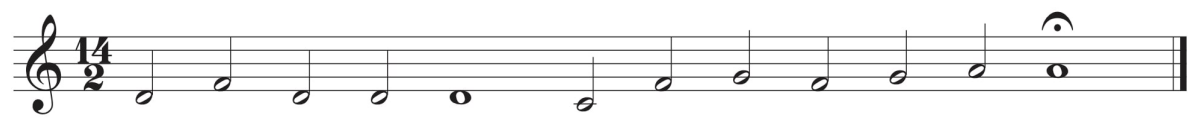

Exemplo 1. Transcriçấo em Dó do cantus firmus executado pelo clarinete na abertura de In Nomine a 3.

Os elementos de referencialidade não se restringem às coleçóes de alturas, mas também estão incorporadas nas estruturas formais da peça. As composições tradicionais do gênero In Nomine recorrem ao uso fidedigno do cantus firmus Gloria tibi Trinitas, este aspecto frequentemente implica em músicas de curta duração. A brevidade temporal nas peças do gênero pode ser verificada ao analisar os 19 In Nomine de Tye compilados por Weidner (1960), estas peças contêm entre 23 e 58 compassos. Este dado indica que o formato de miniatura adotado em In Nomine a 3, com 24 compassos (FERNEYHOUGH, 2001) e cerca de dois minutos de duraçáo (IN NOMINE, 2004), é um importante indício de alusão ao gênero In Nomine e ao estilo composicional de Tye no âmbito da estruturação formal.

Estes recursos referenciais remetem a uma linguagem contrastante ao estilo composicional de Ferneyhough, compositor frequentemente associado à Escola da "Nova Complexidade"5 (PACE, 2015, p. 32; LEVY, 2008, p. 72). Este termo foi proposto por Toop (1988) para designar um conjunto de compositores britânicos que se destacavam, entre outros fatores, pela abordagem peculiarmente intrincada da notação, das estruturas rítmicas e da microtonalidade. Portanto, as estratégias de referencialidade adotadas em In Nomine a 3 apontam para elementos estruturantes do discurso musical que são pouco frequentes no restante da produção de Ferneyhough. Estas estratégias serão discutidas a partir de exemplos no âmbito da forma, das alturas e das organizações paramétricas e temporais.

As próximas etapas do estudo analítico concentram-se na compreensão da estruturação formal e na organização temporal dos eventos em In Nomine a 3, abordando os elementos de referencialidade e discutindo o produto dos procedimentos composicionais de Ferneyhough nesta peça. O intuito é demonstrar como o projeto temático relacionado a Tye implicou em adaptaçôes no pensamento composicional e nos recursos estilísticos comumente empregados por Ferneyhough a fim de incorpo-

5 Existe uma extensa discussão sobre a validade e a relevância do termo "Nova Complexidade" e suas principais características musicais e estéticas, cf. Kozu (2003), Lévy (2008) e Pace (2015). A utilização deste termo neste trabalho tem o intuito de contextualizar o contraste entre a linguagem e os recursos tonais e as estratégias pós-seriais utilizadas por Ferneyhough. 
rar a referencialidade. $\mathrm{O}$ trabalho visa elucidar algumas das estratégias que fornecem coesão formal e organizacional nesta peça, examinando a geração e manipulação do material musical a partir dos resultados dos processos composicionais identificados na partitura. A análise parte do estudo da macroforma (aspectos formais gerais e divisão formal em seções e subseçôes) e caminha em direção ao estudo da microforma (aspectos organizacionais do ritmo nas subseçôes e em compassos individuais). Outros fatores relevantes da referencialidade serão contextualizados de acordo com sua pertinência no estudo das organizaçóes formais e temporais estruturantes da peça.

\section{Estruturaçáo da macroforma}

A primeira etapa da análise consistiu na estruturação da peça no âmbito da macroforma. Uma proposta de representação da análise da forma de In Nomine a 3 é dada na figura 1 . $O$ estudo analítico sugere a existência de duas seçóes nesta peça, nomeadas $S$ e $S$ '. Esta segmentação foi definida a partir de características simétricas encontradas nas duas seçôes: o tamanho idêntico (de 12 compassos cada), a grande similaridade em suas estruturaçôes métricas e o mesmo posicionamento das marcaçôes dos andamentos e de accel. $/$ rall. Estas similaridades subsidiaram uma segunda segmentação da forma em cinco subseçôes para cada seção. As subseçôes foram nomeadas de s 1 a s5 para a seção $S$, e s'1 a s'5 para a seção $S^{\prime}$.

O conjunto de características simétricas apresentadas acima aponta para uma organização tradicional da forma baseada primordialmente na divisão binária da peça, com cada seção apresentando reiteraçóes de seus elementos principais (fórmulas de compasso, marcaçōes e variaçôes de andamento, tamanho e subdivisão das seçôes). Esta abordagem formal é peculiar desta peça e pouco frequente no restante da produção de Ferneyhough, mesmo em comparação com os outros três In Nomine do compositor ${ }^{6}$.
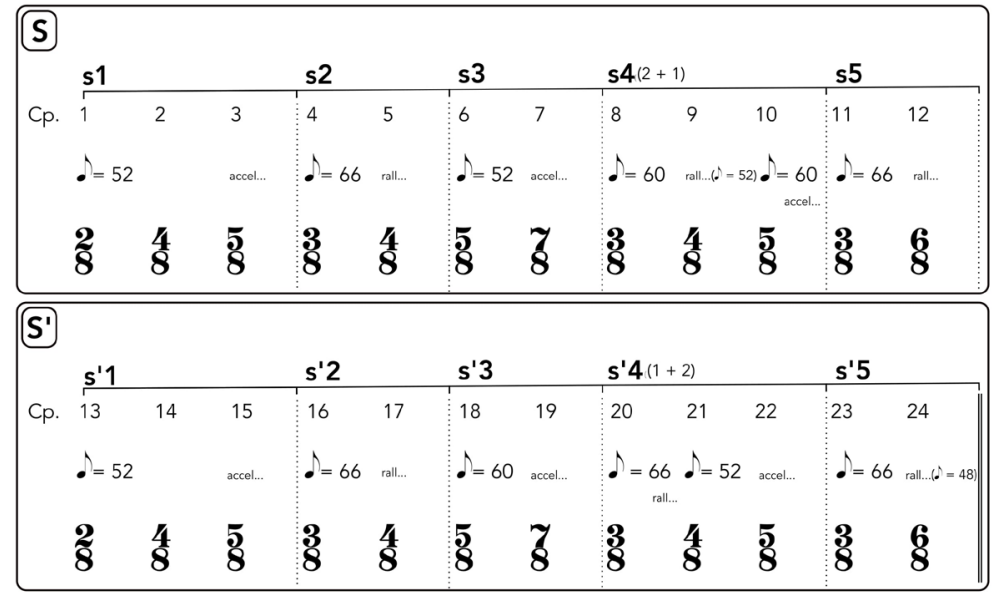

Figura 1. Representação da organização formal de In Nomine a 3

6 Existem outras três peças em alusão ao gênero In Nomine no catálogo de peças do compositor: In Nomine a 5 (2017), In Nomine a 12 (2017) e In Nomine para cello solo (2017). 
"É possível determinar um ponto crucial no modo como Ferneyhough associa a complexidade em relação à forma, não mais no sentido de garantir a unidade formal, mas de embaralhá-la de modo a assegurar uma multiplicidade informal"7 (KOZU, 2003, p. 39). Esta abordagem da complexidade também é recorrente nas organizaçóes paramétricas, através do emprego de fórmulas de compasso com diferentes unidades de tempo ao longo das peças ${ }^{8}$, múltiplas variaçôes de andamento e relaçóes assimétricas no tamanho das seçôes e subseçôes ${ }^{9}$. As relaçôes estruturantes de suas peças baseiam-se ainda na combinação de múltiplas regras e processos simultâneos em diversos parâmetros musicais. Estes processos de geração e manipulação do material musical estão relacionados e podem influenciar uns aos outros (FELLER, 2013, p. 252 e 257). Tais procedimentos evitam reiteraçóes evidentes dos parâmetros musicais e distanciam o discurso de um desenvolvimento motívico tradicional (TOOP, 1995, p. 4). Estes aspectos reforçam a peculiaridade na organização formal simétrica de In Nomine a 3.

Com exceção da estruturação formal simétrica, a maioria das organizaçôes paramétricas (tais como ritmos e alturas) se assemelham ao discurso tradicionalmente adotado pelo compositor. São escassas as reiteraçôes dos materiais musicais encontradas na partitura e, quando ocorrem, sempre remetem aos elementos estilísticos da temática do ciclo, estes aspectos serão investigados detalhadamente adiante. As reiteraçôes identificadas estão localizadas em pontos simétricos da forma, indicando a existência de um recurso unificador na abordagem da referencialidade. Este tratamento contrasta com a maior parte do discurso musical da peça.

Um conjunto de características expostas na figura 1 demonstram os principais indícios de correlação entre a unidade formal e a organização métrica desta peça, são elas: 1) a mudança de fórmula a cada compasso; 2) a utilização de apenas seis fórmulas de compasso, vizinhas e baseadas sobre a mesma unidade de tempo (2/8, 3/8, 4/8, 5/8, 6/8 e 7/8); e 3) o emprego de apenas quatro marcaçóes de andamento, baseadas sobre a colcheia e com valores próximos (48, 52, 60 e 66 bpm). Uma variação sutil na disposição dos andamentos na subseção s' 4 em relação a s 4 é indicada na figura 1 pela notação dos agrupamentos dos compassos $(2+1)$ em s4 e (1+2) em s'4. Esta variação não afeta a identificação desta subseção na macroforma da peça. Nas demais subseçôes não existem mudanças significativas. Além das similaridades na estruturação métrica, a disposição da maioria das marcaçóes de andamento e de rall. e accel. são idênticas para ambas as seçôes.

É relevante detalhar as características e os locais em que o material musical se relaciona estruturalmente com a unidade formal da peça. Essas relaçóes fornecem indícios importantes para a compreensão da unidade formal e da referencialidade. O primeiro exemplo é o cantus firmus tocado pelo clarinete na abertura da peça (vide novamente o exemplo 1). Este trecho é composto por uma melodia de 12 notas, o mesmo número de compassos que compóe cada seção. Essa relação fornece outro indício de que Ferneyhough elaborou a

$7 \quad$ O termo "multiplicidade informal" remete a um princípio importante do pensamento composicional de Ferneyhough: a abordagem não estrita dos processos de geraçâo e manipulação do material musical (FERNEYHOUGH,1999, p. 112). Este é um dos fatores que distanciam os procedimentos composicionais de Ferneyhough daqueles típicos do serialismo integral, por exemplo.

8 Os seis primeiros compassos de In Nomine a 12 (2017), por exemplo. É um trecho composto por seis fórmulas de compasso com unidades de tempo diferentes: 6/8, 13/32, 3/10, 5/20, 2/9 e 5/12 respectivamente. 9 Exemplos relevantes desses procedimentos composicionais são discutidos minuciosamente por Toop (1990; 1995) e Kozu (2003).

ICTUS Music Journal vol. 14 n.1 
forma partindo de referências musicais diretamente associadas ao In Nomine tradicional. O segundo exemplo encontra-se no início do cp. 1, a nota Ré é executada simultaneamente nos três instrumentos, coincidindo com a primeira nota do cantus firmus. O terceiro exemplo é o repouso sobre a tríade maior Fá - Lá - Dó ${ }^{10}$ de maneira simultânea no início dos cps. 4, 12 e 20 (detalhados no exemplo 2). Estes pontos são formalmente equidistantes ${ }^{11}$ cuja harmonia contrasta com a organização das alturas predominante da peça, que é baseada em um conjunto de intervalos dissonantes, especialmente trítonos, sétimas e segundas. Há também o uso frequente de alterações microtonais de quartos e oitavos de tom.

O último exemplo refere-se à utilização de um material escalar nos cps. 11 e 23 (detalhados no exemplo 3), remetendo à tríade maior citada anteriormente. A progressão escalar no cp. 11 não possui qualquer tipo de tratamento que distorça o caráter tonal da progressão, tornando-a evidente. No cp. 23 existem alteraçôes de quartos e oitavos de tom melódicos, harmonicamente as vozes encontram-se em intervalos de segunda. As duas estruturas escalares tem uma relação evidenciada pela recorrência de outros parâmetros musicais, enfatizando a sua relevância formal. Duas vozes são responsáveis pelo material escalar em ambos os trechos, sempre em movimento descendente por graus conjuntos, em colcheias, com articulação marcato e em dinâmica ffe efff subito. Por fim, os trechos estão localizados em subseçôes correspondentes, $s 5$ e s'5 respectivamente. Estes são os compassos que apresentam maior índice de correspondência entre múltiplos parâmetros musicais na peça.

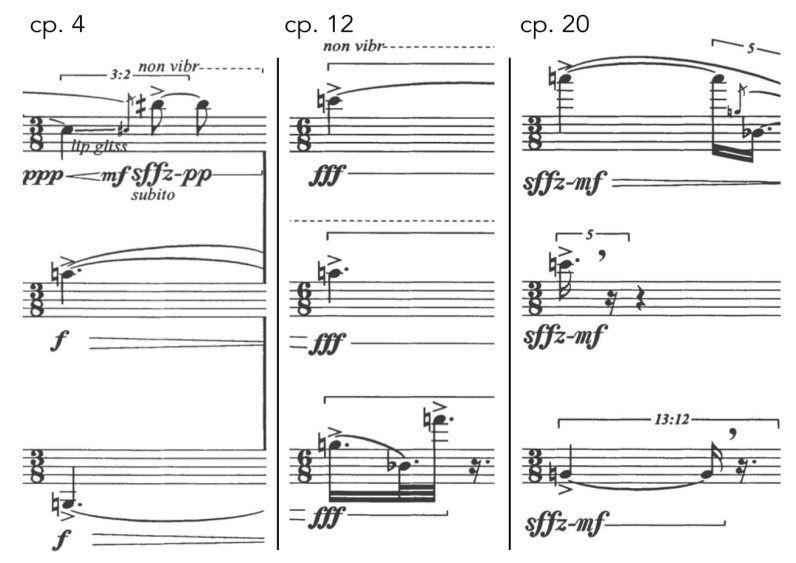

Exemplo 2. Utilização da tríade Fá-Lá-Dó no início do cp. 4 (esquerda), cp. 12 (centro) e cp. 20 (direita) ${ }^{12}$

10 A localização e a posição das tríades nas respectivas oitavas foram desconsideradas.

11 São equidistantes entre si pois existem oito compassos entre cada ocorrência. Também são equidistantes em relação à forma geral da peça, com a primeira ocorrência a quatro compassos do início e a última a quatro compassos do fim.

12 A parte do clarinete encontra-se sempre transposta. 


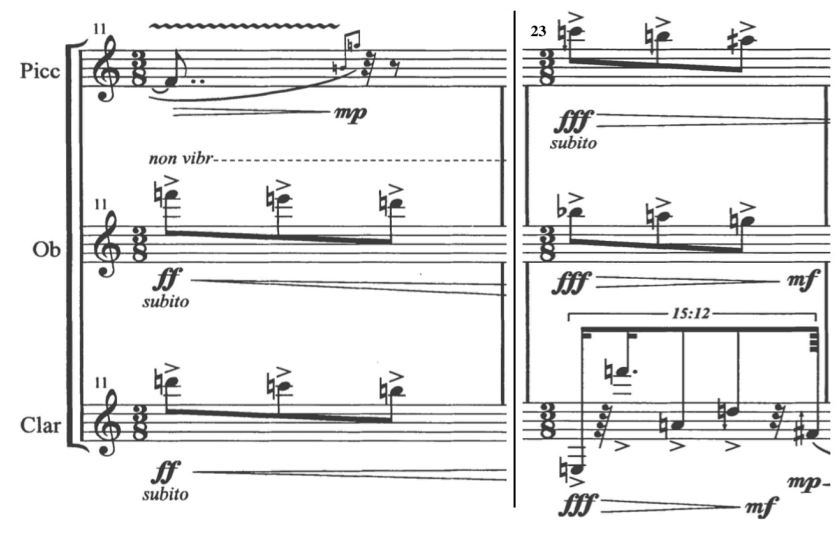

Exemplo 3. Material escalar enfatizado por parâmetros similares no cp. 11 (esquerda) e cp. 23 (direita)

Os indícios de reiteração nos trechos discutidos anteriormente indicam que o compositor interviu diretamente nos processos de geração do material para enfatizar algumas das características referenciais da temática da peça. A referencialidade baseada em um conjunto de materiais tonais representa um contraste significativo com os demais tipicamente empregados no discurso de Ferneyhough. Mesmo se tratando de ocorrências locais e de curta duração, em uma miniatura, tais relaçóes de similaridade e de contraste do material são apreensíveis e constituem fatores significativos para a compreensão do discurso musical da peça pelo ouvinte.

Diversas das características identificadas na análise reforçam a hipótese de que Ferneyhough emprega objetivamente elementos musicais que fazem alusão ao gênero In Nomine, à música renascentista e ao repertório de Tye. Este tratamento baseado na referencialidade é um aspecto primordial do discurso desta peça e é pouco evidente nos outros três In Nomine compostos posteriormente pelo compositor.

Outros princípios organizacionais importantes da peça estấo localizados no âmbito da microforma, especialmente aqueles que dizem respeito aos processos de geração e manipulação das estruturas rítmicas. A relação das organizações paramétricas com a referencialidade ocorre de modo distinto na microforma, revelando aspectos pertinentes do pensamento composicional de Ferneyhough nos diversos níveis de estruturaçáo da peça.

\section{Elementos de coesão na microforma}

A investigação da microforma da peça consiste no estudo das relaçóes musicais no âmbito das subseçóes e dos compassos individuais, apontando indícios locais sobre a coesão formal e a estruturação temporal. A estruturação temporal e as organizaçôes rítmicas são aspectos de grande relevância no estudo dos processos composicionais deste compositor, sendo um tópico recorrente em seus próprios textos. Um aspecto importante nesta etapa é determinar uma abordagem analítica que permita compreender e relacionar esses princípios organizacionais ao pensamento composicional empregado em In Nomine a 3. 
Os estudos analíticos focados nas estruturas temporais e rítmicas por vezes baseiam-se nas relaçôes de similaridade figural, nos padróes de agrupamento e nos princípios de desenvolvimento, variação e transformação em variados níveis "arquitetônicos" - termo utilizado por Cooper e Meyer (1963). O estudo destas hierarquias frequentemente considera uma aproximação tradicional da métrica e das estruturas de desenvolvimento e variação rítmica. Diversos fatores técnicos e estilísticos dificultam uma abordagem única para o repertório do século XX, conforme discute Smither (1964). Autores como Cooper e Meyer (1963) e Hasty (1997) utilizam metodologias analíticas focadas nos aspectos métricos e rítmicos de um amplo repertório, porém prioritariamente tonal e que se estende até o serialismo da Segunda Escola de Viena.

O procedimento de análise de um repertório cujas organizaçôes métricas e rítmicas concentram-se em abordagens e processos composicionais peculiares a um compositor e/ou estética frequentemente demanda o desenvolvimento de aproximações analíticas alternativas, adequadas às especificidades do objeto estudado e às demandas do próprio estudo analítico. Ferneyhough emprega um conjunto de processos para a geração, desenvolvimento e variação das estruturas rítmicas que não se enquadra nos procedimentos típicos do serialismo, por exemplo. Sua abordagem da métrica também não é tradicional. Esses fatores demandam uma aproximação analítica que considere as peculiaridades estruturais dessas organizaçóes paramétricas no contexto da peça analisada e da estética do compositor.

A análise propóe uma abordagem alternativa para a investigação local das organizaçóes temporais e rítmicas, a partir de estratégias que consideram algumas das perspectivas dos processos composicionais adotados pelo compositor, buscando relacionar o produto musical destes processos de geração e manipulação dos materiais (isto é, a notação musical que consta na partitura) ao seu pensamento composicional. A primeira etapa do estudo foca nos aspectos mais amplos da microforma, o das subseções, seguido pelos aspectos mais minuciosos, aqueles relacionados aos agrupamentos rítmicos nos compassos individuais.

\subsection{Perfis de distribuiçáo das densidades de eventos}

Uma das organizaçôes temporais comumente utilizadas pelo compositor é o processo de distribuiçáo das densidades dos eventos musicais ao longo dos compassos (FERNEYHOUGH, 1993, p. 27; TOOP, 1995, p. 4 e 15). Neste contexto, as divisôes dos compassos têm a função hierárquica de delimitar o âmbito de cada processo composicional empregado pelo compositor (FERNEYHOUGH, 1998, p. 52). Ao investigar estes procedimentos no âmbito das subseçôes, é possível observar indícios da organização textural ${ }^{13}$ da peça que não são acessíveis pela análise tradicional da partitura, devido as constantes mudanças de andamento, fórmulas de compasso e do uso de quiálteras.

A figura 2 contém uma representação gráfica do desenvolvimento das densidades em In Nomine a 3. As curvas retratam o perfil de evolução e de direcionalidade das densidades de eventos em cada subseção da peça. Existem duas categorias de

13 Neste trabalho, o termo "textura" corresponde à característica polifônica resultante da combinação vertical das vozes instrumentais, focando predominantemente no aspecto das organizaçôes rítmicas e seus desdobramentos no discurso temporal das subseçốes da peça. 
curvas nesta figura, uma para a evolução de cada instrumento e outra para a evolução da resultante geral dos três instrumentos. O valor abaixo das curvas corresponde à densidade de eventos, indicando a média de eventos (ataques) por segundo em cada compasso da respectiva subseçáa ${ }^{14}$. Esta abordagem permite uma representação acessível da evolução temporal das densidades individuais e gerais, tornando uma análise comparativa dos valores viável devido à conversão das complexas estruturas rítmicas para valores médios absolutos baseados na quantidade de "eventos por segundo".

A análise das curvas de densidade indica a existência de recorrências nos perfis de evolução e direcionalidade das densidades dos eventos entre as subseçôes idênticas, isto é, entre s1 e s'1, s2 e s'2, etc. As recorrências ocorrem tanto nas curvas gerais quanto nas partes instrumentais individuais, como na parte do oboé em s1, s2 e s3 se comparado com s'1, s'2 e s'3. A localização dos valores de densidade que apresentam recorrência indica que as reiterações não são fortuitas, mas o produto dos processos composicionais de Ferneyhough no nível de geração do material. Visando fornecer subsídios para a compreensão de alguns dos elementos musicais resultantes desses processos composicionais, detalharemos quatro exemplos de reiteração do material e das organizaçóes paramétricas.

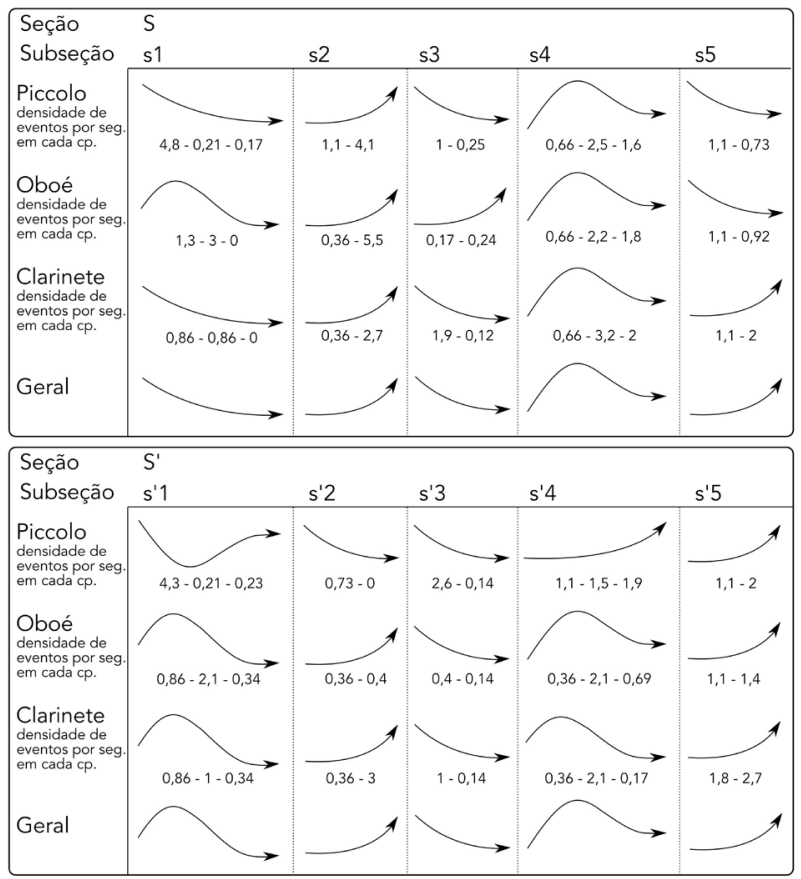

Figura 2. Representação do desenvolvimento temporal dos perfis de densidade de eventos em In Nomine a 3

14 A média de eventos foi obtida a partir das seguintes etapas: 1) identificação do número de ataques em um determinado compasso; 2) divisão da quantidade de ataques pelo número de unidades de tempo da respectiva fórmula de compasso; 3) conversão da média de eventos obtida para segundos. Exemplo na subseção s1: 11 ataques / 2 tempos $=5,5$ eventos por colcheia. Uma colcheia a $52 \mathrm{bpm}$ equivale a 1,15 segundos. Por fim, $5,5 / 1,15=4,78$ eventos por segundo. 
O primeiro exemplo refere-se ao valor de 1,1 eventos por segundo, este índice é o mais recorrente na peça, com sete ocorrências. Este valor localiza-se sempre em compassos 3/8 e por quatro vezes em locais simétricos da forma, são eles: no cp. 11 (primeiro de s5) em todos os instrumentos, no cp. 20 (primeiro de s'4) no piccolo e no cp. 23 (primeiro de s'5) no piccolo e no oboé. É relevante lembrar que os cps. 11, 20 e 23 são três pontos onde existem materiais referenciais da temática, em formato escalar, triádico e escalar, respectivamente.

O segundo exemplo consiste nas seis ocorrências do valor de 0,36 eventos por segundo, localizadas em compassos $3 / 8$ e em pontos simétricos da forma, onde existem materiais referenciais da temática. Ocorrem sempre no oboé e no clarinete, nos cps. 4 (primeiro de s2), 16 (primeiro de s'2) e 20 (primeiro de s'4). Cabe reiterar quais são os materiais referenciais nos respectivos trechos. $\mathrm{O}$ cp. 4 contém a primeira ocorrência da tríade Fá - Lá - Dó, o cp. 16 apresenta uma correspondência organizacional paramétrica em relação ao cp. 4 - ainda que com outra formação harmônica (uma variação da tríade original, no formato Mi - Lá - Fá ascendentemente). O cp. 20 contém outra ocorrência da tríade Fá - Lá - Dó e, conforme citado previamente, a parte do piccolo neste compasso possui o valor de 1,1 eventos por segundo.

O terceiro exemplo refere-se ao valor de 0,86 eventos por segundo, localizado em pontos simétricos da forma, nos cps. 1 e 2 (primeiro e segundo de s1, respectivamente) no clarinete e no cp. 13 (primeiro de s'1) no oboé e clarinete. Por fim, existem três ocorrências do valor de 0,17 eventos por segundo, uma para cada instrumento, em pontos não-simétricos da forma, mas sempre em compassos 5/8. As ocorrências estão localizadas no cp. 3 (terceiro de s1) no piccolo, no cp. 6 (primeiro de s3) no oboé e no cp. 22 (terceiro de s'4) no clarinete.

A análise dos valores e dos perfis das curvas de densidade reforçam a correlação entre a referencialidade, a coesão formal discutida na macroforma e os princípios organizacionais dos materiais no âmbito da microforma. É possível sugerir que a recorrência nos valores e nas curvas de perfis de densidade é o produto de múltiplos processos composicionais, pois as similaridades emergem da combinação de múltiplos parâmetros tais como andamentos, quantidade de eventos por compasso e quiálteras empregadas.

\subsection{Análise das estruturas rítmicas a partir da reconstruçáo em OpenMusic}

A etapa final do estudo concentrou-se em investigar as relaçôes presentes nos compassos individuais. Este é um aspecto importante na verificação dos processos organizacionais locais do ritmo que são pouco acessíveis a partir da análise tradicional da partitura. A investigação busca identificar os indícios de coesão das estruturas de quiálteras e como estas se relacionam com os outros aspectos estruturantes nos níveis mais abrangentes da microforma e da macroforma.

A análise tradicional da partitura permite identificar o uso recorrente de quiálteras que abrangem compassos completos, conforme exemplificado na figura 3 . Este padráo não ocorre nos compassos que contêm os materiais referenciais e que estejam localizados em pontos simétricos da forma, tais como os cps. 4 (primeiro de s2), 11 (primeiro de s5), 16 (primeiro de s'2) e 23 (primeiro de s'5). Estes padróes de estruturação local do material rítmico corroboram o contraste na abordagem da 
referencialidade em relação aos demais materiais da peça, enfatizando os pontos simétricos da forma discutidos ao longo deste estudo.
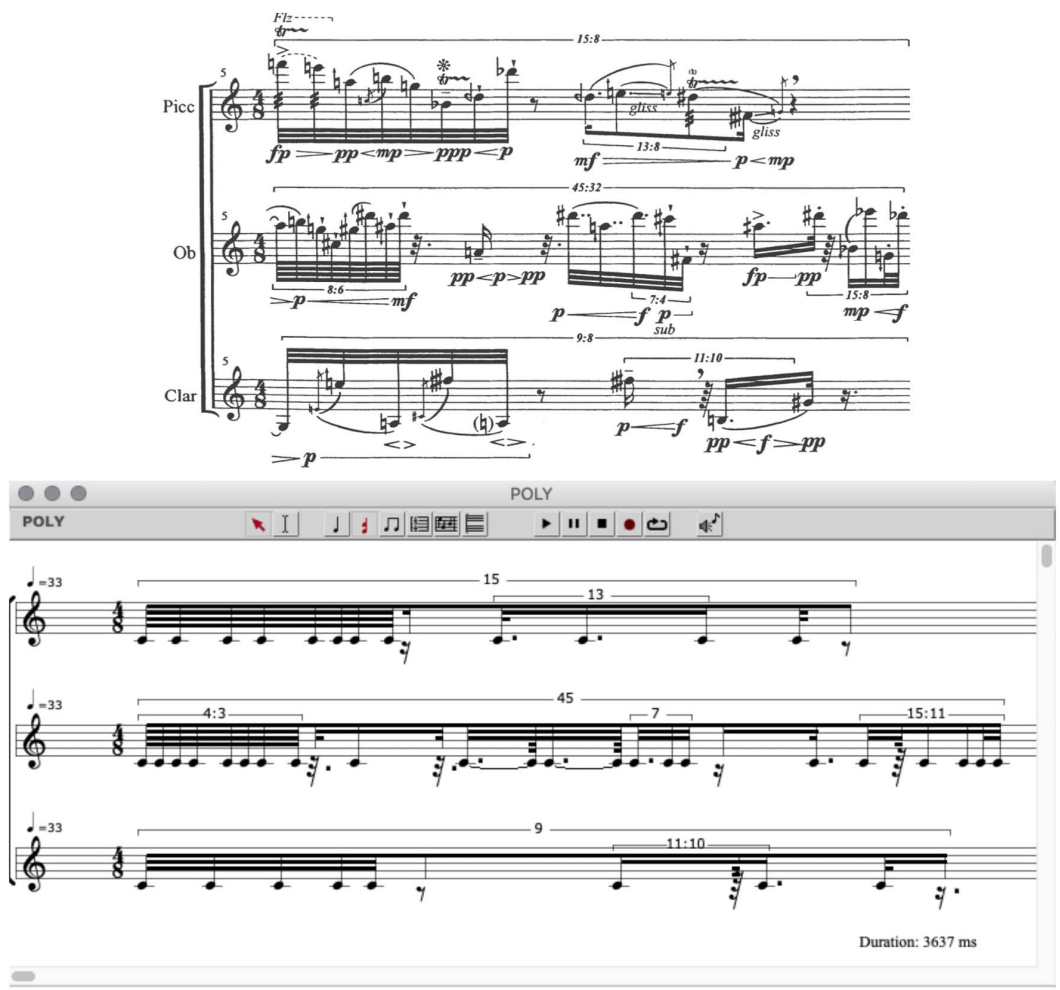

Figura 3. Exemplo da representação rítmica do compasso 5 (acima) da peça em OpenMusic (abaixo)

A análise das estruturas rítmicas locais da peça partiu da reconstrução de In Nomine a 3 no programa OpenMusic ${ }^{15}$. Este software é frequentemente usado pelo compositor para geração de material desde o início da década de 1990, conforme discutem Malt (1999) e Kozu (2003). Entre os principais procedimentos composicionais de Ferneyhough no OpenMusic, destaca-se a geração de estruturas rítmicas baseadas na manipulação de conjuntos numéricos. Frequentemente, a manipulação é focada em procedimentos simples de permutação, interpolação, substituição e variação, mas que fornecem resultados de proporções estruturais potencialmente intrincadas (MALT, 1999, p. 81-85).

Devido a natureza numérica desses processos de geraçấo do material musical, os princípios organizacionais do ritmo não podem ser identificados diretamente a partir da notação musical disponível na partitura. A transcriçấo rítmica em OpenMusic fornece subsídios que permitem identificar alguns dos princípios de coesão do material rítmico, baseando-se na análise dos conjuntos numéricos obtidos na transcrição. 


\begin{tabular}{|c|c|c|c|}
\hline & Árvore de ritmo & $\begin{array}{l}\text { Representação } \\
\text { fracionária }\end{array}$ & $\begin{array}{l}\text { Máximo Divisor } \\
\text { Comum (MDC) }\end{array}$ \\
\hline Piccolo & 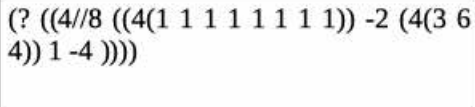 & 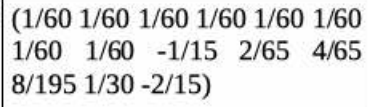 & 5 \\
\hline Oboé & 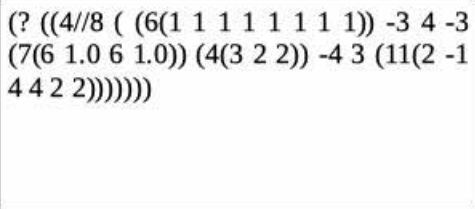 & 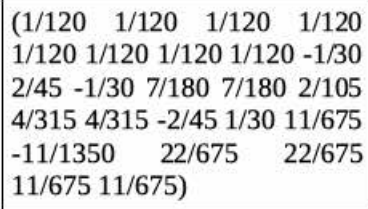 & 15 \\
\hline Clarinete & 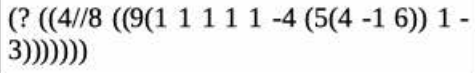 & 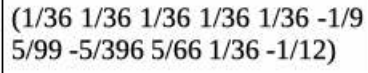 & 3 \\
\hline
\end{tabular}

Tabela 1. árvore de ritmo e representação fracionária das duraçôes fornecidas pelo programa OpenMusic para cada instrumento no compasso 5 de In Nomine a 3.

O procedimento de reconstrução rítmica em OpenMusic partiu da criação de uma lista numérica denominada "árvore de ritmo" 16 para cada compasso de cada instrumento. A partir de cada árvore foi possível derivar as respectivas duraçóes em formato fracionário, sendo então utilizado na análise. A figura 3 apresenta a reconstrução do compasso 5 da peça em OpenMusic. Em seguida, a tabela 1 apresenta a representação numérica em formato de árvore e em formato fracionário para cada instrumento neste compasso.

A representação fracionária das durações fornece uma correlação entre a hierarquia da árvore de ritmo utilizada no OpenMusic e a notação tradicional. Por exemplo, a fração $1 / 8$ significa a subdivisão de uma semibreve em oito partes, o que representa uma colcheia. Seguindo este mesmo princípio, é possível especificar quiálteras tais como a fração $1 / 12$, que representa a colcheia de uma tercina de colcheias e a fração $1 / 20$, que representa uma semicolcheia de uma quintina de semicolcheias. Esta representação fracionária permite investigar, a partir de relaçóes numéricas, as complexas estruturas rítmicas baseadas em quiálteras frequentes em In Nomine a 3.

As frações correspondentes às duraçóes foram analisadas em cada compasso da peça com base no valor de Máximo Divisor Comum (MDC). O MDC fornece a figura rítmica comum de maior valor dentro de um respectivo compasso. Com esse valor é possível inferir indícios locais de coesão rítmica e padróes de recorrência do material musical em toda a peça.

16 "Árvore de ritmo" é um termo utilizado para designar o princípio de organização hierárquica das estruturas rítmicas em OpenMusic baseada nas subdivisóes de figuras rítmicas. Este princípio regula a criação das listas numéricas a partir da partitura original. Uma discussão detalhada desses tópicos pode ser encontrada em JACQUEMARD et al. (2015) e MALT (1999). 

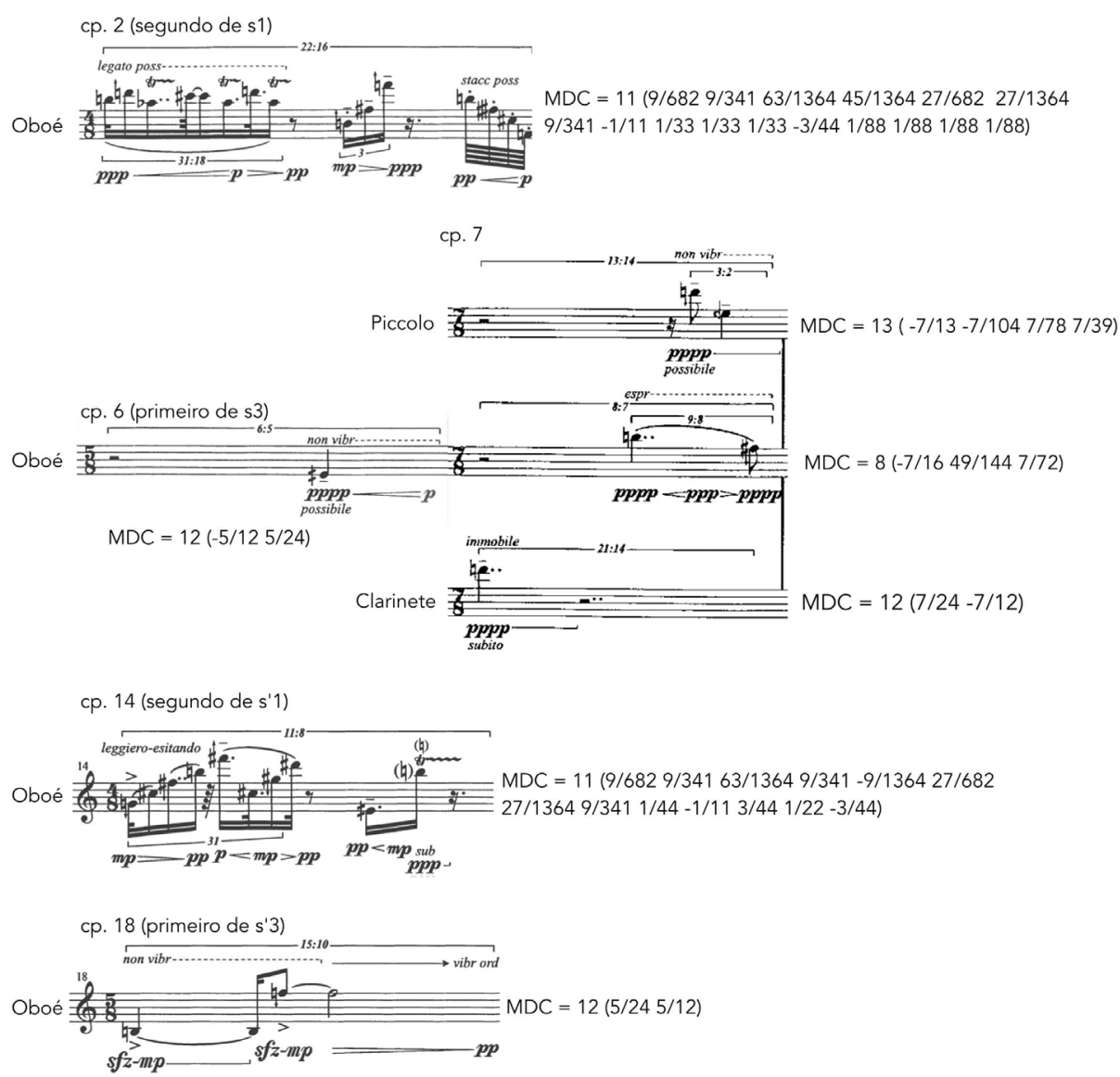

Figura 4. exemplos dos padrôes de recorrência a partir da análise numérica fracionária e do MDC

A figura 4 reúne um conjunto de exemplos de correlaçóes das organizações rítmicas distribuídas na peça. A recorrência nos valores do MDC em diferentes compassos indica dois tipos de similaridade entre as estruturas rítmicas: nas quiálteras principais empregadas nos compassos - por exemplo, nos cps. 2 e 14 no oboé; ou nas representaçōes fracionárias do ritmo em quiálteras não-correlatas - por exemplo, nos cps. 6, 7 e 18 no oboé. Existem outros padróes de recorrência que não são identificáveis através do MDC e demandam outras estratégias de análise numérica. A maioria das correlaçóes numéricas encontradas estão localizadas em pontos simétricos da forma. Por exemplo, na parte do oboé nos cps. 2 (segundo de s1) e 14 (segundo de s'1) coincidem as quiálteras proporcionais (11:8 vs. 22:16) e com mesmo MDC (11). Outro exemplo, também na parte do oboé, são os cps. 6 (primeiro de s3) e 18 (primeiro de s'3), em que coincidem o MDC (12) e as representaçóes fracionárias do ritmo $(5 / 12$ e 5/24).

Existem relaçôes similares em compassos que contêm os materiais referenciais da temática. Por exemplo, o cp. 4 (primeiro de s2), em que há a primeira ocorrência 
da tríade Fá - Lá - Dó, possui correspondências com o cp. 16 (segundo de s’2). Estes compassos compartilham o mesmo MDC (6 para o piccolo e 8 para o oboé e clarinete) e as mesmas representaçôes fracionárias (correlatos para 3/8 e 5/8 e coincidentes para 1/6 e 5/24). Estas correlações numéricas confirmam os indícios de similaridade discutidos previamente na análise, abrangendo os elementos da referencialidade em múltiplos níveis da organização formal da peça, inclusive no âmbito dos compassos individuais e suas estruturas rítmicas.

O valor do MDC geral de um compasso fornece um importante indício unificador das duraçôes nesta divisão da microforma da peça. Porém, para analisar os agrupamentos e células rítmicas contidas em diferentes quiálteras e em diferentes compassos, é necessário recorrer ao estudo comparativo dos denominadores fracionários dos agrupamentos rítmicos isolados. Esta estratégia permite inferir relaçóes de proporcionalidade entre agrupamentos rítmicos distintos em múltiplas localizaçôes da peça, valores numéricos que também são inacessíveis pela análise da notação na partitura. Neste estudo, as relaçôes de proporcionalidade foram consideradas com base nos valores idênticos e nos múltiplos dos denominadores fracionários.

O primeiro aspecto examinado foi a proporcionalidade entre as quiálteras similares contidas em outras quiálteras e localizadas em andamentos distintos. Para exemplificar este princípio, todas as septinas da peça foram consideradas: nos cps. 1 (7:6 em 3:2 a $52 \mathrm{bpm}), 18(7: 5$ a $60 \mathrm{bpm})$ e $22(7: 5$ em 17:10 a $52 \mathrm{bpm}) \mathrm{da}$ parte do piccolo; nos cps. 10 (7:5 em 7:5 a $60 \mathrm{bpm}), 15$ (7:5 a $52 \mathrm{bpm})$ e 21 (7:5 em 24:16 a $52 \mathrm{bpm})$ da parte do clarinete; e no cp. 5 (7:4 em 45:32 a $66 \mathrm{bpm}) \mathrm{da}$ parte do oboé. Com exceção da ocorrência no oboé, as demais septinas apresentaram proporcionalidade entre os denominadores, todos são múltiplos de 28. A figura 5 demonstra graficamente as relaçóes fracionárias nos respectivos trechos citados da peça. As representações fracionárias contidas na figura são restritas aos valores correspondentes às septinas a fim de simplificar a visualização.

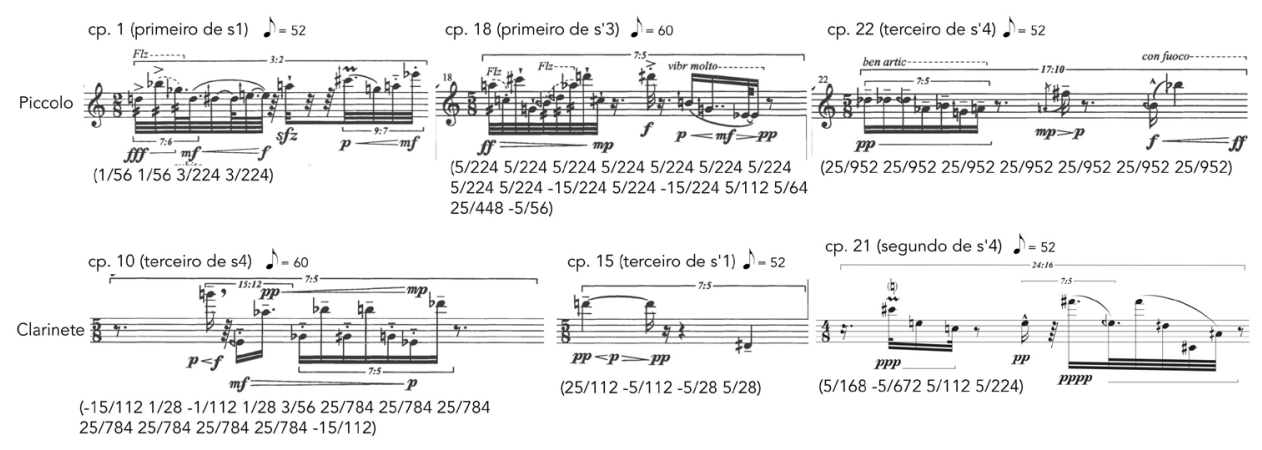

Figura 5. Exemplos de proporcionalidade nos denominadores fracionários das septinas baseados em múltiplos de 28

Existem três parâmetros envolvidos na determinação da representação fracionária: o andamento, a quiáltera interna e a externa (quando se aplica). Após esta 
primeira parte da análise, é possível sugerir que as similaridades numéricas encontradas nos variados agrupamentos e em células rítmicas distintas são o produto da combinação de um processo ou regra de geração unificadora do ritmo. A exceção na ocorrência do oboé reforça que as relaçôes de similaridade não são exclusivamente baseadas na septina. Estruturas semelhantes podem ser verificadas em outras quiálteras que são recorrentes ao longo da peça, tais como as sextinas (6:5) no cp. $6 \mathrm{e}$ seus múltiplos, como a quiáltera de 18:12 no cp. 12, a quiáltera de 24:16 no cp. 21, mas não na quiáltera de 18:14 no cp. 17.

O segundo aspecto examinado foi a proporcionalidade entre os denominadores fracionários de materiais rítmicos que não compartilham características comuns evidentes. $\mathrm{O}$ primeiro exemplo reside em três ocorrências de agrupamentos rítmicos baseados em fusas e semifusas, nos cps. 5, 9 e 24 da parte do piccolo e no cp. 5 da parte do oboé. $\mathrm{O}$ denominador da representação fracionária em todos os casos são proporcionais entre si a partir do número 60. Embora contidos em quiálteras e em compassos de andamentos distintos, esses agrupamentos rítmicos locais apresentam estruturas figurais similares e durações proporcionais.

As relaçóes proporcionais das representaçóes numéricas identificadas nos ritmos se estendem aos numeradores das representaçôes fracionárias (vide figura 6). Este aspecto indica proporcionalidade no agrupamento e/ou no encadeamento de eventos musicais para um ou múltiplos compassos. Um exemplo desta organização ocorre no cp. 7 (segundo de s3), em que há uma relação de múltiplos de 7 entre os numeradores da representaçáo fracionária para os três instrumentos. No cp. 19, correspondente simétrico da forma (segundo de s'3), existe a mesma relação numérica nos numeradores por múltiplos de $7 \mathrm{em}$ uma organização rítmica que não apresenta similaridade visível na notação em relação ao primeiro caso. Nos dois trechos a fórmula do compasso é idêntica (7/8), mas com o emprego de andamentos (52 bpm no cp. 7 e 60 bpm no cp. 19) e de quiálteras distintas.
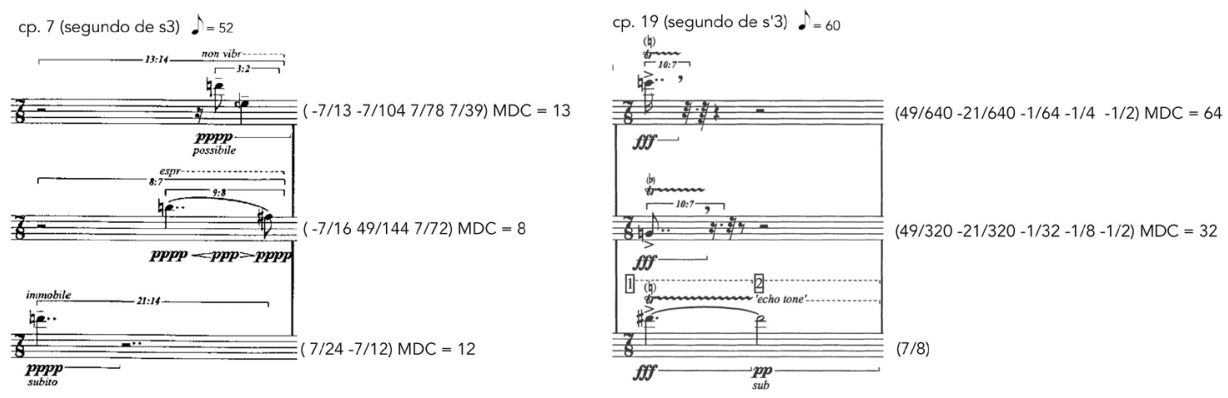

Figura 6. Similaridade dos numeradores das representaçôes fracionárias no cp. 7 (esquerda) e cp. 19 (direita)

Existe outra similaridade relevante entre estes dois trechos. No cp. 7 existe a concatenação das entradas dos instrumentos em formato piramidal iniciado pelo clarinete, seguido pelo oboé e finalizado no piccolo. No cp. 19 ocorre uma estrutura de ataque e ressonância simultânea entre os três instrumentos, com menor duração no piccolo, seguida pelo oboé e maior duração no clarinete. A similaridade reside 
na correspondência entre os gestos musicais dos dois trechos e na ordem de entrada dos instrumentos, que no cp. 7 corresponde ao inverso da duração das notas sustentadas no cp. 19.

Estes exemplos sobre a organização rítmica na microforma indicam que Ferneyhough baseou-se em princípios de geração e estruturação do material rítmico que extrapolam a similaridade figural e gestual evidentes na notação musical tradicional. Estas relações estão presentes em diversos níveis da estruturação rítmica e são dependentes de um conjunto de elementos paramétricos. Apesar das múltiplas regras e processos de geração derivados de manipulaçóes paramétricas e numéricas, o produto final, ou seja, o material musical que consta na partitura, fornece indícios relevantes que permitem acessar uma ampla gama das relaçóes estruturais que organizam e fornecem coesão ao discurso musical da peça. Estes elementos estão inter-relacionados em múltiplos níveis da forma e da organização temporal e rítmica, indicando uma intrincada interdependência entre os variados princípios que regem a elaboração do pensamento composicional de In Nomine a 3.

\section{Consideraçóes finais}

O trabalho analítico propôs uma reflexão sobre In Nomine a 3 do compositor inglês Brian Ferneyhough a partir do estudo das relações formais, estruturais e temporais dos materiais disponíveis na partitura. Uma aproximação analítica alternativa foi elaborada a fim de elucidar princípios importantes do pensamento composicional, focando na visualização, compreensão e discussão de elementos estruturantes do discurso musical que não são acessíveis pela análise tradicional da partitura.

O desenvolvimento de uma abordagem analítica adequada às ferramentas e aos processos composicionais se mostra particularmente relevante neste repertório, no qual parte do processo criativo baseia-se em princípios extramusicais, neste caso, em organizações e manipulações numéricas para a geração de material. A investigação dessas relaçóes numéricas permitiu acessar e compreender os meandros de um discurso musical regido por múltiplos processos inter-relacionados. Este é um dos aspectos da "multiplicidade" que caracteriza a poética de Ferneyhough e permeia diversas instâncias do seu processo criativo, desde os materiais, suas articulaçôes formais e temporais, até a escuta.

O estudo das organizações paramétricas fornece subsídios para uma aproximação objetiva aos elementos estruturantes do pensamento composicional de Ferneyhough que visa, em última instância, estimular o ouvinte "a uma escuta constantemente ativa e autocritica, considerando a ausência de modelos e/ou normas interpretativas aceitas universalmente" (KOZU, 2003, p. 37). Portanto, o emprego de múltiplos procedimentos técnicos é um meio de propor um discurso musical baseado no "potencial expressivo dos estados ambíguos e voláteis" (FERNEYHOUGH, 1994, p. 129).

A partir da investigação das peculiaridades formais, da referencialidade e da organização temporal em In Nomine a 3, é possível sugerir que a articulação dos processos técnicos com as propostas estéticas do compositor, combinada a uma "escuta ativa" e "autocrítica" pode proporcionar uma assimilação embasada do "fenômeno estético" proposto por Ferneyhough. Por fim, o estudo buscou contribuir com uma abordagem que possa ser adaptada e aplicada em outras peças que sejam baseadas em princípios composicionais e estéticos similares. 


\section{Referências}

COOPER, Grosvenor; MEYER, Leonard. The rhythmic structure of music. University of Chicago Press, 1963.

DONINGTON, Robert; DART, Thurston. The Origin of the in Nomine. Music \& Letters, v. 30, n. 2, p. 101-106, 1949.

FELLER, Ross. Resistant strains of postmodernism, the music of Helmut Lachenmann and Brian Ferneyhough. In: LOCHHEAD, Judy; AUNER, Joseph (Org.). Postmodern music/postmodern thought. Routledge, 2013. p. 249-262.

FERNEYHOUGH, Brian. Collected writings. Amsterdam: Harwood, 1998

. In Nomine a 3: para piccolo, oboé e clarinete. London: Edition Peters, 2001. Partitura. $7 \mathrm{p}$.

. La "musique informelle". In: SZENDY, Peter (Org.). Compositeurs d'aujourd'hui: Brian Ferneyhough. Paris: L'Harmattan, 1999. p. 109-117.

. The tactility of time. Perspectives of new music, Seattle, v. 31, n. 1 p. 20-30, 1993.

FERNEYHOUGH, Brian; BOROS, James. Composing a Viable (If Transitory) Self. Perspectives of new music, Seattle, v. 31, n. 1, p. 114-130, 1994.

FITCH, Lois. Brian Ferneyhough. Bristol: Intellect Books, 2013.

HASTY, Christopher. Meter as rhythm. Oxford University Press, 1997.

HEPBURN, Allan. Piano Miniatures: An Essay on Brevity. Gettysburg Review, v. 19, n. 1, p. 89-105, 2006.

IN NOMINE: The Witten In Nomine Broken Consort Book. Ensemble Recherche. Áustria: KAIROS, 2004. CD.

JACQUEMARD, Florent; DONAT-BOUILLUD, Pierre; BRESSON, Jean. A structural theory of rhythm notation based on tree representations and term rewriting. In: International Conference on Mathematics and Computation in Music. London: Springer, 2015. p. 3-15.

KOZU, Fernando Hikori. A complexidade em Brian Ferneyhough: aspectos de comunicação e inteligibilidade musical. São Paulo, 2003. 110 p. Dissertação. PUC, São Paulo, 2003.

LÉVY, Fabien. Inintelligible, injouable, incomprehensible: la complexité musicale est-elle analytique, instrumentale, perceptive ou hétéronome? In: INIESTA, Rosa (Org.). Revista de investigación musical: territorios para el arte, Valencia: Universidad de Valencia, 2008, p. 61-87.

MALT, Mikhail. Brian Ferneyhough et l'aide informatique à l'écriture. Brian Ferneyhough 
and Computer-Assisted Composition. In: SZENDY, Peter (Org.). Compositeurs d'aujourd'hui: Brian Ferneyhough. Paris: L'Harmattan, 1999. p. 61-106.

PACE, Ian. Positions, Methodologies and aesthetics in the published discourse about Brian Ferneyhough: a critical study. Journal for New Music and Culture, London, v. 2015, n. 11, p.1-73, 2015.

REESE, Gustave. The Origin of the English "In Nomine". Journal of the American Musicological Society, California, v. 2, n. 1, p. 7-22, 1949.

SMITHER, Howard E. The Rhythmic Analysis of 20th-Century Music. Journal of Music Theory, v. 8, n. 1, p. 54-88, 1964.

TOOP, Richard. Four facets of the New Complexity. Contact: A Journal for Contemporary Music, n. 32, p. 4-50, 1988.

. Brian Ferneyhough's Lemma-Icon-Epigram. Perspectives of new music, Seattle, v. 28, n.2, p. 52-100, 1990.

. On Superscriptio: an interview with Brian Ferneyhough and an analysis. Contemporary Music Review, London, v. 13, n. 1, p. 3-17, 1995.

WEIDNER, Robert Wright. The Early In Nomine: A Genesis of Chamber Music. Rochester, 1960. Tese de doutorado - University of Rochester, New York, 1960. 